\title{
Genetic variability in CMS backcross generations and their maintainers in eggplant (Solanum melongena L.)
}

\author{
Karmvir S. Garcha, A. S. Dhatt* and M. K. Sidhu \\ Department of Vegetable Science, Punjab Agricultural University, Ludhiana-141004 (Punjab), INDIA \\ *Corresponding author. E-mail: ajmerdhatt@gmail.com \\ Received: December 20, 2016; Revised received: March 26, 2017; Accepted: August 27, 2017
}

\begin{abstract}
Twelve genotypes of eggplant in $\mathrm{BC}_{3}, \mathrm{BC}_{4}$ and $\mathrm{BC}_{5}$ generations of CMS-lines derived from Solanum aethiopicum $\times$ Solanum melongena cross along with their maintainers were evaluated for eighteen quantitative characters at Punjab Agricultural University Ludhiana. Analysis of variance depicted significant variation $(P \leq 0.05)$ for all the characters in all generations. High PCV and GCV values were observed for fruit length, fruit girth, fruit weight, number of fruits plant ${ }^{-1}$ and yield plant ${ }^{-1}$ in all generations indicating high variability in the germplasm. High heritability coupled with high genetic advance was found for peduncle length, fruit length, fruit girth, fruit weight, number of fruits plant $^{-1}$ and yield plant ${ }^{-1}$ in all generations indicating the predominance of additive gene action for these traits. Thus, selections can be made from present germplasm for the development of improved CMS inbred lines with varying fruit traits.
\end{abstract}

Keywords: CMS, Eggplant, GCV, Heritability, PCV, Percent GA

\section{INTRODUCTION}

Eggplant (Solanum melongena L.), popularly known as brinjal, aubergine or guinea squash is a diploid $(2 n=2 x=24)$ and often cross-pollinated vegetable crop. It is an economically important horticultural crop especially in South - East Asia and, exploitation of genetic diversity is important for raising the yield levels. Selection of genotypes based on yield, as such is difficult as most of the yield related characters are inherited and being governed by the large number of cumulative, duplicate and dominant genes. Therefore, generation of variability, selection of superior genotypes from the variable genetic stock and development of superior genotypes remains a basic breeding strategy in crop improvement programmes (Appalaswamy and Reddy, 2004).

In eggplant, on the basis of fruit size even the varieties exhibit variability leading to classification of specie melongena into three botanical varieties viz., esculentum (round or egg shaped fruits), serpentinum (long, slender fruits) and depressum (small fruits) (Choudhury,1976). Further, variability in colour like deep-purple, purple, light-purple, scarlet, green, white and striped is also present and, exploited as per consumers' preference. Accordingly, in heterosis breeding parents are also chosen based upon the size, shape, colour and clustering pattern of the fruits. There is a report of induced cytoplasmic male sterility (CMS) in eggplant through wide hybridization between $S$. aethiopicum and S. melongena (Khan and Issihiki, 2010). Male sterility is an established genetic tool that evaded hand emasculation and pollination during hybrid seed production and, exploited world-wide in large number of field and vegetable crops (Fang et al., 1997; Zhao and Gai, 2006; Chen et al., 2008; Deol et al., 2013; Shen Xian-hua et al., 2013 and Islam et al., 2015). Thus, we made an attempt to cross $S$. aethiopicum and $S$. melongena to induce non-pollen formation type of cytoplasmic male sterility. This was further transferred into diverse genetic backgrounds of different shapes, sizes, colours and clustering patterns to use in heterosis breeding programme. The genetic variability for agronomic and morphological traits have been reported by many workers in cultivated and wild relatives of eggplant (Prohens et al., 2005; Rodríguez-Burruezo et al., 2008; Muñoz-Falcón et al., 2009; Prabhu et al., 2009; Dhaka and Soni, 2012; Kumar et al., 2013 and Singh et al., 2014) but is not available among male-sterile lines of different genetic backgrounds. Therefore, in present study attempt was made to assess the information on magnitude of genetic variability in $\mathrm{BC}_{3}$, $\mathrm{BC}_{4}$ and $\mathrm{BC}_{5}$ generations of CMS lines and their maintainers derived from interspecific cross of $S$. aethiopicum $\times S$. melongena.

\section{MATERIALS AND METHODS}

Experimental site: The experiment was conducted at Vegetable Research Farm, Department of Vegetable Science, Punjab Agricultural University, Ludhiana which is $30^{\circ} 54^{\prime} \mathrm{N}$ latitude and $75^{\circ} 48^{\prime} \mathrm{E}$ longitude at a mean height of 247 meters above sea level. The mean maximum and minimum temperature show considera- 
ble fluctuations during the summer, while minimum temperature falls below freezing point accompanied by frosty spells during winter. The average rainfall is about $500-700 \mathrm{~mm}$, most of which is normally received from July-September.

Planting material and treatments: In this study $\mathrm{BC}_{3}$, $\mathrm{BC}_{4}$ and $\mathrm{BC}_{5}$ progenies of twelve genotypes viz., $\mathrm{CB}$ 99 - 231, SR 5, SR 93-213, SR 232, P 67, BL 12-4, BL 201, BL 214, BL 216, BL 219, BR 104 and MR 319 developed from cross of $S$. aethiopicum $\times S$. melongena along with their respective maintainer recurrent parents were subjected to variability analysis. The maintainer genotypes and advanced backcross generations were evaluated for various morphological traits using phenotypic measures. Maintainers and sterile backcross generations were raised during 2015-16 at Vegetable Research Farm, Department of Vegetable Science, Punjab Agricultural University, Ludhiana. The experiment was laid in Randomized Complete Block Design with three replications for each generation. To ensure optimum fruit setting on cytoplasmic male-sterile lines, each flower was pollinated everyday with the pollen collected by the pollen collector. This process was continued for entire period of flowering (eight weeks). The data obtained from all the generations was assessed statistically for various yield and disease related traits viz., plant height $(\mathrm{cm})$, plant spread $(\mathrm{cm})$, petiole length $(\mathrm{cm})$, leaf length $(\mathrm{cm})$, leaf width $(\mathrm{cm})$, pedicel length $(\mathrm{mm})$, calyx size $(\mathrm{mm})$, petal length $(\mathrm{mm})$, petal width $(\mathrm{mm})$, stamen size (mm), pistil size (mm), days to $50 \%$ flowering, peduncle length $(\mathrm{cm})$, fruit length $(\mathrm{cm})$, fruit girth $(\mathrm{cm})$, fruit weight $(\mathrm{g})$, number of fruits plant ${ }^{-1}$ and yield plant ${ }^{-1}$ (kg).

Estimation of genetic parameters: Means of the data collected across seasons were subjected to analysis of variance using CPCS-1 (Cheema and Singh, 1990) and significant means were compared using least significant difference at $\mathrm{P} \leq 0.05$. Genetic parameters like genotypic variance $(\mathrm{Vg})$ and phenotypic variance $(\mathrm{Vp})$ were obtained according to Burton and Devance, (1953) as follows:

$$
\begin{aligned}
& V g=\frac{M S g-M S e}{r} \\
& V p=V g+V e
\end{aligned}
$$

Where, $\mathrm{MSg}=$ mean square of genotypes, $\mathrm{MSe}=$ mean square of error, $r=$ number of replications, and $\mathrm{Ve}=$ environmental variance

The mean values were used for genetic analyses to determine phenotypic coefficient of variation (PCV) and genotypic coefficient of variation (GCV), according to Burton, (1952) as follows:

$G C V(\%)=\frac{\sqrt{V g}}{\overline{\mathrm{x}}} \times 100$.

$$
P C V(\%)=\frac{\sqrt{V p}}{\overline{\mathrm{x}}} \times 100
$$

Where, $\mathrm{Vg}=$ genotypic variance, $\mathrm{Vp}=$ phenotypic variance, and $\bar{x}=$ genotypic mean

The broad sense heritability $\left(\mathrm{H}^{2}\right)$ and genetic advance (GA) was computed according to the procedure suggested by Johnson et al., (1955) as follows:

$$
\begin{aligned}
& \mathrm{H}^{2}=\frac{\frac{V g}{V p} \times 100 x}{\mathrm{VA}}=\sqrt{V p} \times H^{2} \times \mathrm{k} \\
& \mathrm{G}
\end{aligned}
$$

Where, $\mathrm{k}=$ differential selection constant (2.06) at 5\% selection, $\mathrm{Vp}=$ phenotypic variance, $\mathrm{Vg}=$ genotypic variance, and $\mathrm{H}^{2}=$ heritability in broad sense

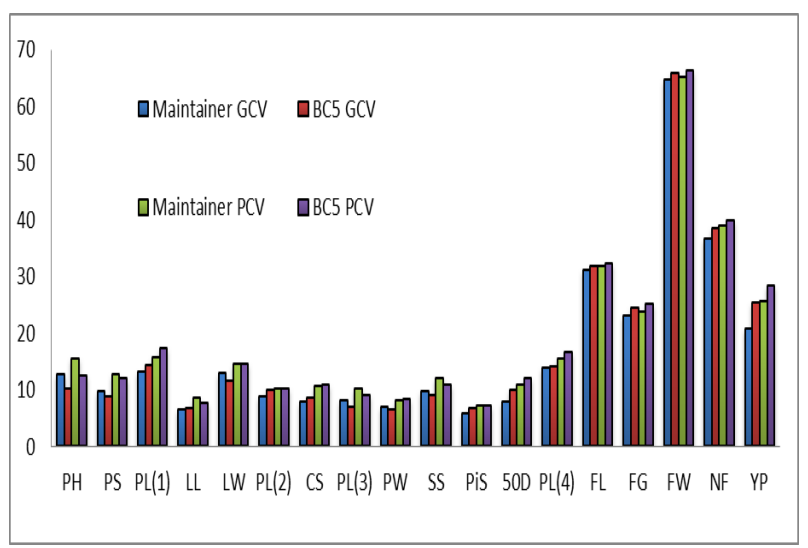

Fig. 1. Phenotypic co-efficient of variation (PCV \%) and Genotypic co-efficient of variation (GCV \%) in maintainers and $C M S B_{5}$ generation of eggplant genotypes.

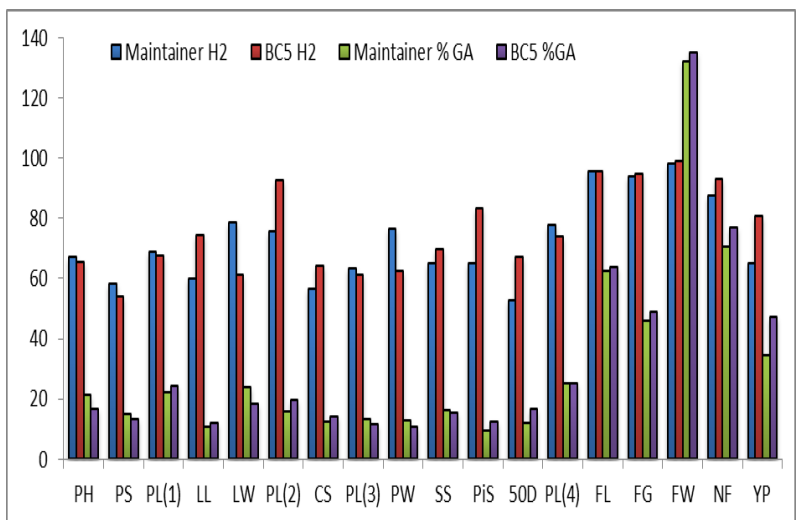

Fig. 2. Heritability $\left(H^{2}\right)$ and Genetic advance (\%GA) in maintainers and CMS $\mathrm{BC}_{5}$ generation of eggplant genotypes.

Where, $\mathrm{PH}=$ plant height, $\mathrm{PS}=$ plant spread, $\mathrm{PL}(1)=$ petiole length, $\mathrm{LL}=$ leaf length, $\mathrm{LW}=$ leaf width, $\operatorname{PL}(2)=$ pedicel length, $\mathrm{CS}=$ calyx size, $\mathrm{PL}(3)=$ petal length, $\mathrm{PW}=$ petal width, $\mathrm{SS}=$ stamen size, $\mathrm{Pis}=$ pistil size, $50 \mathrm{D}=$ days to $50 \%$ flowering, $\mathrm{PL}(4)=$ peduncle length, $\mathrm{FL}=$ fruit length, $\mathrm{FG}=$ fruit girth, $\mathrm{FW}=$ fruit weight, $\mathrm{NF}=$ number of fruits plant ${ }^{-1}$ and $\mathrm{YP}=$ yield plant $^{-1}$. 
Karmvir S. Garcha et al. / J. Appl. \& Nat. Sci. 9 (3): 1854 -1860 (2017)

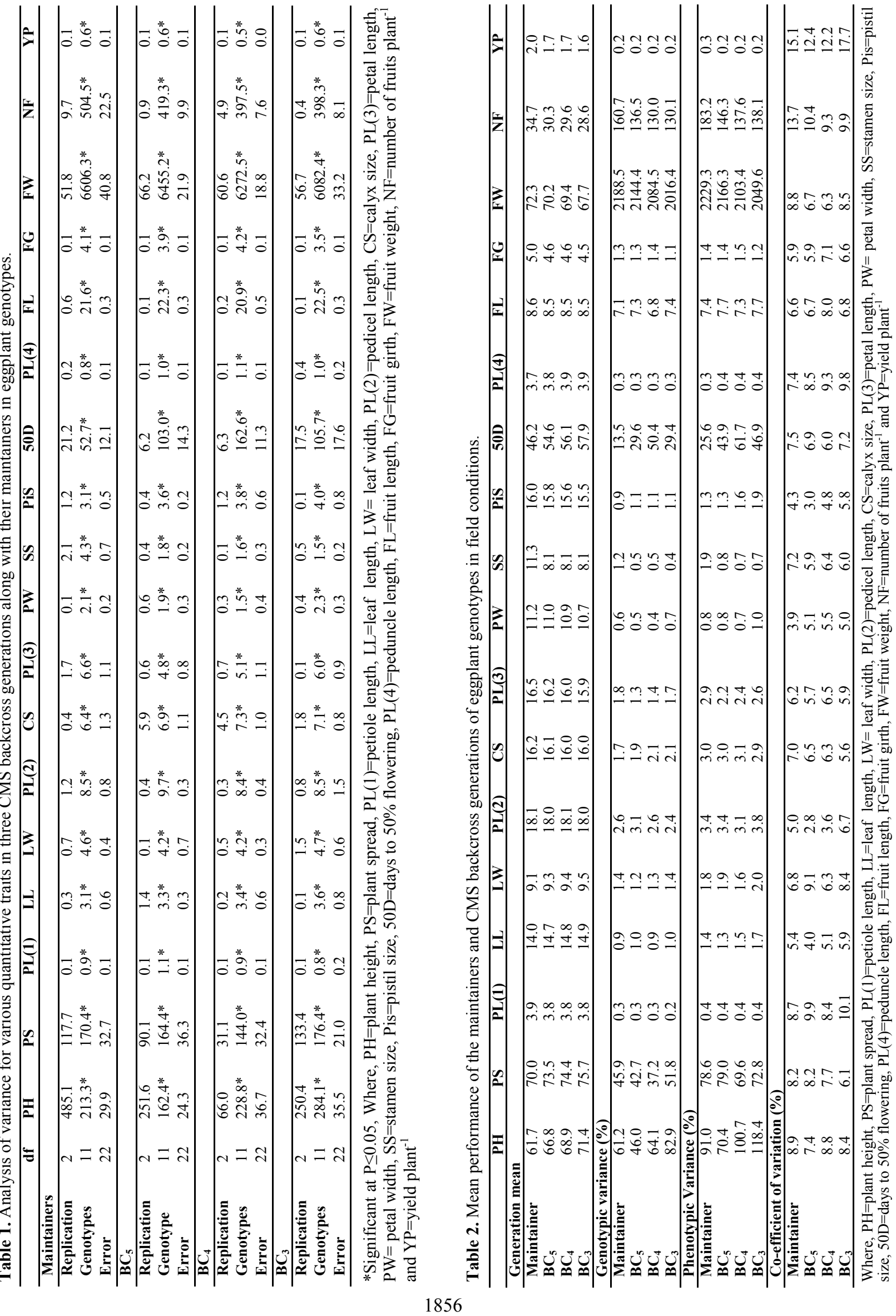


Karmvir S. Garcha et al. / J. Appl. \& Nat. Sci. 9 (3): 1854 -1860 (2017)

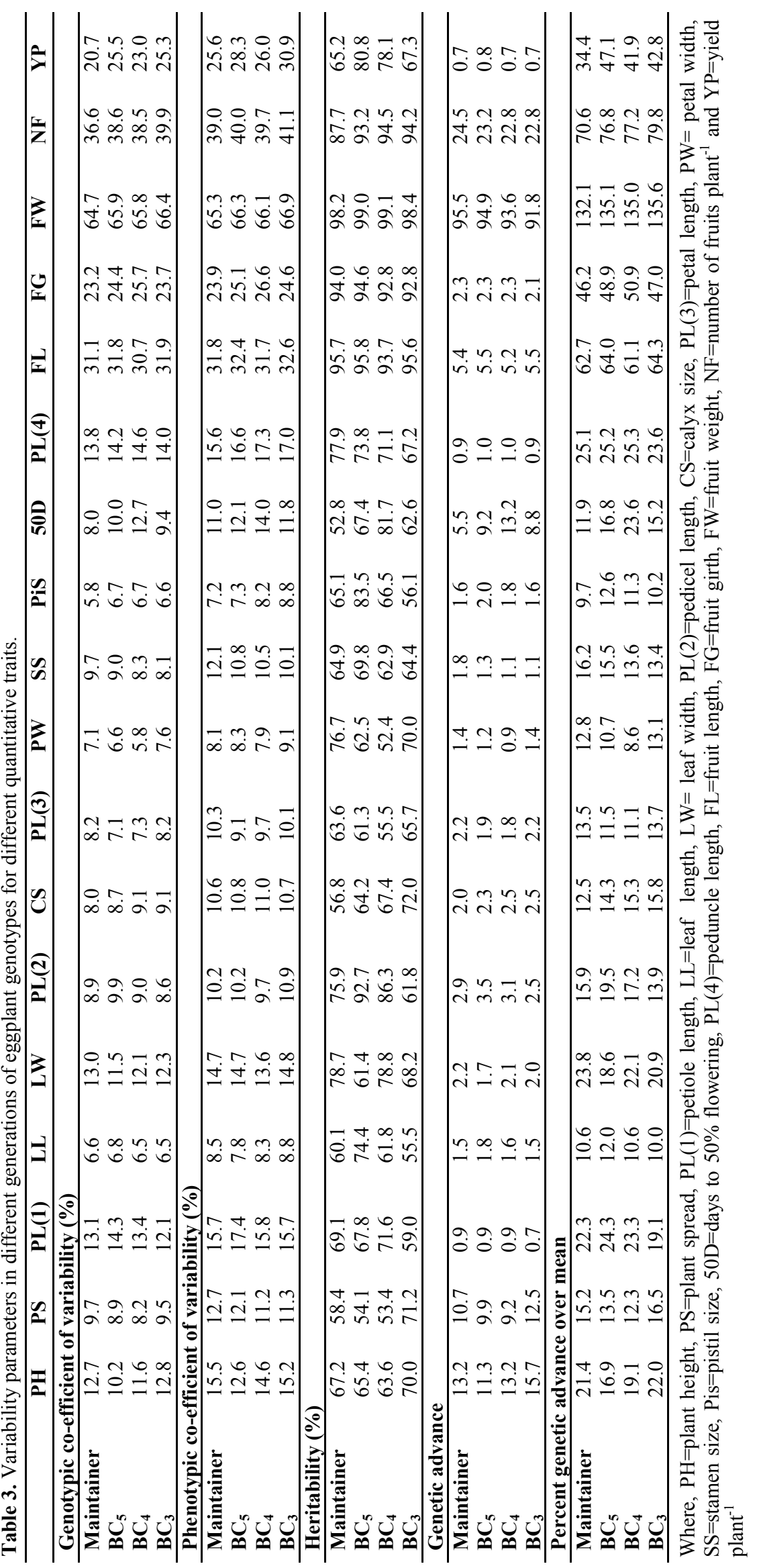


Genetic advance percentage of mean (\%GA) was calculated as follows:

$$
G A(\%)=\frac{G A}{\mu} \times 100
$$

Where, $\mathrm{GA}=$ genetic advance, and $\mu=$ grand mean

Categories of the coefficients of variation: Coefficients of variation were categorized according to Sivsubramanian and Menon, (1973) as: Low (0-10\%), Medium (11-20\%) and High (> 20\%). Whereas, categories of heritability values were accordance to Robinson et al., (1949) as Low (0-30\%), Medium (31-60\%) and High $(>60 \%)$. Further, the percent genetic advance $(\%$ GA) over mean was also classified as Low $(<10 \%)$, Medium (10-20\%), High ( $>20 \%$ ).

\section{RESULTS AND DISCUSSION}

Analysis of variance: The analysis of variance for eighteen quantitative traits of all the three backcross generations along with their maintainers in twelve genotypes is presented in Table 1 . The results represented that mean sum of squares of the traits in three backcross generations of CMS-lines and their maintainers differed significantly $(\mathrm{P} \leq 0.05)$ demonstrating vast amount of variability for various growth and yield attributes. It depicts the transfer of cytoplasmic malesterility into different backcross generations derived from diverse maintainers. This variability in different maintainers and CMS generations is very important in the development of diverse CMS lines (A-lines) for use in heterosis breeding of CGMS (cytoplasmic genetic male-sterility system) system. The selection could be made from these backcross populations for succeeding backcrosses with their respective recurrent parents for further improvement. The variability available for the eighteen traits under study in twelve genotypes was investigated using $\mathrm{PCV}, \mathrm{GCV}, \mathrm{H}^{2}$ and genetic advance (Table 2, 3).

Estimation of variability parameters: Mean and variance values for all of the traits under study exhibited difference in alloplasmic male-sterile backcross generations of all the genotypes $\left(\mathrm{BC}_{3}, \mathrm{BC}_{4}\right.$ and $\left.\mathrm{BC}_{5}\right)$. The mean values of vegetative growth traits revealed that all male-sterile lines had more vegetative growth than their fertile counterparts (Table 2), which may be attributed to lesser fruit setting and yield plant ${ }^{-1}$ due to artificial pollination. But in $\mathrm{BC}_{5}$, days to $50 \%$ flowering along with vegetative growth viz. mean plant height, plant spread, leaf length, leaf width were less compared to $\mathrm{BC}_{3}$ and $\mathrm{BC}_{4}$. Similarly, there was an increase in calyx size, petal length and width, pistil size, fruit weight, number of fruits plant ${ }^{-1}$ and yield plant ${ }^{-1}$ in $\mathrm{BC}_{5}$ than $\mathrm{BC}_{3}$ and $\mathrm{BC}_{4}$ indicating desirable restoration of recurrent parental characters with advancement in backcross generations. Overall, the population mean of $\mathrm{BC}_{5}$ was more near towards the recurrent parents mean compared to $\mathrm{BC}_{3}$ and $\mathrm{BC}_{4}$. Analysis of genotypic and phenotypic variances resulted in differential genotypic contribution in hereditary character also imparting the importance of environmental variance in the phenotypic expression of the analysed traits. The highest proportion of genetic variance was presented in petiole length followed by peduncle length, fruit girth and yield plant ${ }^{-1}$ with least environmental influence in expression of these characters. Similar results of high genotypic variance ranging from 22.28 to 61296.0 and phenotypic variances ranging from 35.51 to 61319.20 for various traits have been observed in eggplant by Mili et al., (2014).

Selection of desirable and appropriate parents is one of most important step in any successful breeding programme. Good cultivars are obtained only, if the parents used in the program were suitable. Therefore, emphasis was given to choose appropriate parents in order to obtain desirable genotypes. Use of agronomically superior, diverse and locally adapted genotypes in the breeding programme will ensure the recovery of high proportion of progenies with wide adaptation; thus the variability in parental genotypes for various morphological traits was studied.

The co-efficient of variations (GCV and PCV) for the various morphological traits reported in various generations are presented in Table 3. These co-efficient of variations were classified into low, moderate and high scale (Sivsubramanian and Menon, 1973). In all the generations; plant spread, leaf length, pedicel length, calyx size, petal length, petal width, stamen size and pistil size exhibited low GCV while high variability was exhibited by fruit length followed by fruit girth, mean fruit weight, number of fruits plant ${ }^{-1}$ and yield plant $^{-1}$. All other traits had shown an intermediate genotypic component of variation. The high GCV gives an indication of justifiable variability among the genotypes with respect to these characters and therefore gives scope for improvement through selection. In general, high PCV was there than the corresponding GCV for all traits under study (Figure 1). The variation between GCV and PCV depicts the predominant environmental role in expression of these characters. Selection for improvement of characters with high GCV will be rewarding in this situation. Similarly, high GCV and PCV for various traits in eggplant have been reported by many investigators viz., Madhavi et al., (2015) for number of fruits plant ${ }^{-1}(65.21,65.62)$, fruit weight $(59.32,59.42)$, fruit yield plant ${ }^{-1}(55.36$, $56.10)$ and fruit diameter $(31.02,31.43)$; Roychowdhury, (2011) for number of fruits plant ${ }^{-1}$ (41.76, 43.32) and fruit weight $(36.10,37.96)$; Lokesh et al., (2013) for plant height $(24.31,24.75)$, plant spread (39.66, 39.68), fruit diameter $(20.43,20.68)$, fruit weight $(31.92,31.94)$ and fruit yield plant $^{-1}(37.07$, 37.26). Along with these, high variability coefficients in eggplant for number of fruits plant ${ }^{-1}$, leaf width and fruit length were reported by Singh et al., (2014) while 
for fruit weight and number of fruits plant ${ }^{-1}$ by Singh and Kumar (2005) and Mohanty (2002).

Estimation of heritability $\left(\mathrm{H}^{2}\right)$ and genetic advance: The progress and success of any breeding program is dependent upon the degree and the nature of the variability present in in various traits viz., genotypic and non-genotypic variation. Since most of the economic characters (e.g. fruit traits and yield) are governed by quantitative genes and have complex inheritance, various environmental conditions greatly influence them. The study of heritability and genetic advance is thus very important for estimating the scope of improvement with selection. Therefore, heritability (broad sense) was estimated and computed for different traits across three backcross generations of CMS lines along with their maintainers (Table 3 ). The heritability percentage was classified into low, medium and high according to Robinson et al., (1949). The traits viz., plant height, pedicel length, stamen size, peduncle length, fruit length, fruit girth, fruit weight, number of fruit plant ${ }^{-1}$ and yield plant ${ }^{-1}$ had high heritability $\left(\mathrm{H}^{2}\right)$ values in all the generations (Table 3 ). In maintainer lines all characters exhibited high heritability $(>60 \%)$ except plant spread (58.4) and calyx size (56.8), where moderate heritability was present. Similarly, in $\mathrm{BC}_{5}$ generation only plant spread (54.1); in $\mathrm{BC}_{4}$, plant spread (53.4) and petal length (55.5) and, in $\mathrm{BC}_{3}$, petiole length (59.0), leaf length (55.5) and pistil size (56.1) exhibited moderated heritability, whereas high heritability was revealed by all other traits in all these backcross generations. No character in all the generations depicted low heritability.

The use of heritability estimates alone do not provide any indication of the genetic progress that would result from selection of best plants. However, along with phenotypic variance and selection intensity, these estimates can compute response to selection or genetic advance, which is more helpful in the selecting desirable and promising lines (Roham et al., 2003).

The percent genetic advance over mean was also classified into three categories viz., low, moderate and high. High $\% \mathrm{GA}$ in all generations was found in case of days to $50 \%$ flowering, peduncle length and all yield related fruit traits viz. fruit length, girth, weight besides number of fruits and yield plant ${ }^{-1}$ (Table 3 ). In maintainer lines highest genetic gain or $\%$ GA value was reported for fruit weight (132.1) followed by number of fruits plant ${ }^{-1}$ (70.6), fruit length (62.7), fruit girth (46.2), yield plant ${ }^{-1}$ (34.4), peduncle length (25.1) leaf width (23.8), petiole length (22.3) and plant height (21.4) while it was lowest for pistil size (9.7). Whereas, all other traits exhibited moderate percent genetic advance over mean. In all the CMS backcross generations also, highest \%GA was found for fruit weight followed by number of fruits plant ${ }^{-1}$, fruit-length, fruitgirth, yield plant ${ }^{-1}$ and peduncle length. Along with these in $\mathrm{BC}_{5}$ high percent genetic advance was also found for petiole length, in $\mathrm{BC}_{4}$ for days to $50 \%$ flowering, petiole length and leaf width while in $\mathrm{BC}_{3}$ for plant height and leaf width. All other traits in all the backcross generations exhibited moderate percent genetic advance except petal width in $\mathrm{BC}_{4}$. High heritability and high \% GA was found for all the yield related traits in all the generations (Figure 2) which is an indication of prevalence of additive gene-action, where selection can be effective (Panse, 1957). In $\mathrm{BC}_{5}$ generation plant spread, petiole length, peduncle length and all yield traits displayed high heritability along with high percent genetic advance demonstrating importance of selection for further improvement (Figure 2). While, all other traits displayed high heritability but low percent genetic advance indicating predominance of non-additive gene action, where hybridization for improvement could be followed and selection will not be effective. Similar results of high heritability and percent genetic advance in cultivated eggplant for number of fruits plant ${ }^{-1}(92.9,82.96)$, fruit weight $(90.4,71.33)$ and total yield $(59.1,23.82)$ were reported by Roychowdhary (2011). Senapati et al, (2009) for number of fruits plant ${ }^{-1}(96.51,73.26)$, fruit weight (96.01, 49.30) and fruit yield plant ${ }^{-1}$ (92.76, 75.52); Vidhya and Kumar (2015) for fruit girth (96.34, $54.35)$, fruit weight $(95.66,48.96)$, fruit length $(73.35$, $37.48)$, no. of fruits plant ${ }^{-1}(94.09,40.52)$ and yield plant $^{-1}(87.43,38.50)$. Apart from these studies, Singh and Kumar (2005) also reported high heritability and $\%$ GA for fruit weight, no. of fruits plant ${ }^{-1}$ and yield plant $^{-1}$ while Golani et al. (2007) reported high heritability and \% GA for fruit length, girth and weight.

\section{Conclusion}

Genetic variability was studied to find out the diversity among three generations of CMS lines along with their maintainers in twelve genotypes. There was significant difference among genotypes for all the traits studied in all the generations. Minute differences between PCV, GCV along with high estimates of heritability for most of the traits examined revealed the heritable nature of variability. Heritability and genetic advance as percent of mean was high for majority of yield contributing fruit traits in all the generations indicating predominance of additive gene action and selection will be effective for the improvement of these traits. Therefore, the CMS inbred lines that could be used as Alines in CGMS hybrid development programme could be developed from the present germplasm.

\section{REFERENCES}

Appalaswamy, A. and Reddy, G.L.K. (2004). Genetic divergence and heterosis studies in mungbean (Vigna radiata L. Wilczek). Legume Research, 27(2):115-118

Burton, G.W. (1952). Quantitative inheritance in grasses. In: Proc $6^{\text {th }}$ Int. Grassland congress 7:273-283

Burton, G.W. and Devane, E.H. (1953). Estimating heritabil- 
ity in tall fescue (Festuca arundinacea) from replicated colonial material. Agronomy Journal, 45:478-481

Cheema, S.S. and Singh, B. (1990). CPCS-1: A computer programs package for the analysis of commonly used experimental design. Punjab Agricultural University, Ludhiana, India

Chen, Y.M., Wang, Y. and Zhang, Y.P. (2008). A new carrot $\mathrm{F}_{1}$ hybrid 'Jinhong No. 5'. China Vegetables, 4:40-41

Choudhury, B. (1976). Brinjal (Solanum melongena). In: Simmonds NW, eds., Evolution of crop plants. Longman Inc., London and New York, pp. 278 - 279

Deol, J.S., Shivanna, K.R., Prakash, S. and Banga, S.S. (2003). Enarthrocarpus lyratus-based cytoplasmic male sterility and fertility restorer system in Brassica rapa. Plant Breeding, 122:438-440

Dhaka, S.K. and Soni, A.K. (2012). Genetic variability in brinjal (Solanum melongena L.). Asian Journal of Horticulture, 7(2):537-540

Fang, Z., Sun, P., Liu, Y., Yang, L., Wang, X., Hou, A. and Bian, C. (1997). A male sterile line with dominant gene (Ms) in cabbage (Brassica oleracea var. capitata) and its utilization for hybrid seed production. Euphytica, 97:265-268

Golani, I.J., Mehta, D.R., Naliyadhara, M.V., Pandya, H.M. and Purohit, V.L. (2007). A Study on genetic diversity and genetic variability in brinjal. Agricultural Science Digest, 27(1):22-25

Islam, A., Mian, M.A.K., Rasul, G., Bashar, K. and Johora, F.T. (2015) Development of Component Lines (CMS, Maintainer and Restorer lines) and their Maintenance Using Diversed Cytosources of Rice. Journal Rice Research, 3:140

Johnson, H.W., Robinson, H.E. and Comstock, R.E. (1955). Estimates of genetic and environmental variability in soybeans. Agronomy Journal, 47:314-318

Khan, M.M.R. and Isshiki, S. (2010). Development of the Male-sterile Line of Eggplant Utilizing the Cytoplasm of Solanum aethiopicum L. Aculeatum Group. Journal of Japanese Society for Horticultural Science, 79 (4):348-353

Kumar, S.R., Arumugam, T., Anandakumar, C.R. and Premalakshmi, V. (2013) Genetic variability for quantitative and qualitative characters in Brinjal (Solanum melongena L.) African Journal of Agricultural Research, 8(39):4956-4959

Lokesh, B., Reddy, P.S., Reddy, R.V.S.K. and Sivaraj, N. (2013). Variability, heritability and genetic advance studies in Brinjal (Solanum melongena L.). Electronic Journal of Plant Breeding, 4(1):1097-1100

Madhavi, N., Mishra, A.C., Om Prasad, J. and Bahuguna, N. (2015) Studies on variability, heritability and genetic advance in brinjal (Solanum melongena L.). Plant Archive 15(1):277-281

Mili, C., Bora, Das, C. and Paul, S.K. (2014) Studies on variability, heritability and genetic advance in Solanum melongena L. (Brinjal) genotypes. Direct Research Journal of Agriculture and Food Science, 2(11): 192-194

Mohanty, B.K. (2002). Variability, heritability and genetic advance studies in brinjal (Solanum melongena L.). Indian Journal of Agricultural Research, 36(4):290-292
Muñoz-Falcón, J.E., Prohens, J., Vilanova, S. and Nuez, F. (2009). Diversity in commercial varieties and landraces of black eggplants and implications for broadening the breeders' gene pool. Annals of Applied Biology, $154: 453-465$

Panse, V.G. (1957). Genetics of quantitative characters in relation to plant breeding. Indian Journal of Genetics, 17:318-328

Prabhu, M., Natarajan, S. and Pugalendhi, L. (2009). Genetic parameters in eggplant (Solanum melongena) backcross progenies. American - Eurasian Journal of Sustainable Agriculture, 3(3):275-279

Prohens, J., Blanca, J.M. and Nuez, F. (2005). Morphological and molecular variation in a collection of eggplants from a secondary center of diversity: Implications for conservation and breeding. Journal of American Society for Horticultural Science, 130:54-63

Robinson, H.F., Comstock, R.E. and Harvey, P.H. (1949). Estimation of heritability and the degree of dominance in corn. Agronomy Journal, 41:353-359

Rodríguez-Burruezo, A., Prohens, J. and Nuez, F. (2008). Performance of hybrids between local varieties of eggplant (Solanum melongena) and its relation to the mean of parents and to morphological and genetic distances among parents. European Journal of Horticultural Science, 73:76-83

Roham, M.M., Igbal, A.S.M., Arifin, M.S., Akhtar, Z. and Husanuzzaman, M. (2003). Genetic variability, correlation and path analysis in mungbean. Asian J. Plant Sci., 2:1209-1211

Roychowdhury, R., Roy, S. and Tah, J. (2011) Estimation of heritable components of variation and character selection in eggplant (Solanum melongena L.) for mutation breeding programme. Continental Journal of Biological Science, 4(2): 31-36

Senapati, N., Mishra, H.N., Bhoi, M.K., Dash, S.K. and Prasad, G. (2009). Genetic variability and divergence studies in brinjal (Solanum melongena L.). Vegetable Science, 36(2):150-154

Shen, Xian-hua, Yan, S., Huang, R., Zhu, S., Xiong, H. and Shen, L. (2013). Development of Novel Cytoplasmic Male Sterile Source from Dongxiang Wild Rice (Oryza rufipogon) Rice Sci., 20(5):379-382

Singh, M.K., Yadav, J.R. and Singh, B.M. (2014). Genetic variability and heritability in brinjal (Solanum melongena L.). HortFlora Research Spectrum, 3(1):103 $-105$

Singh, O. and Kumar, J. (2005). Variability, heritability and genetic advance in brinjal. Indian Journal of Horticulture, 62(3):265-267

Sivsubramanian, S., Menon, M.P. (1973). Genotypic and phenotypic variability in rice. Madras Agricultural Journal, 60:1093-1096

Vidhya, C. and Kumar, N. (2015) Genetic variability studies in brinjal (Solanum melongena) for fruit yield and quality. Electronic Journal of Plant Breeding, 6(3):668-671

Zhao, T.J. and Gai, J.Y. (2006). Discovery of new malesterile cytoplasm sources and development of a new cytoplasmic-nuclear male-sterile line NJCMS3A in soybean. Euphytica, 152:387-396 